International Journal of Instruction

e-ISSN: 1308-1470 • www.e-iji.net

Article submission code

20200427071442

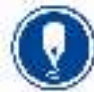

Received: 27/04/2020

Revision: 06/11/2020
April 2021 • Vol.14, No.2

p-ISSN: 1694-609X

pp. 953-968

Accepted: 29/11/2020

OnlineFirst: 13/03/2021

\title{
Understanding Directed Motivational Currents among Chinese EFL Students at a Technological University
}

\section{Chili Li}

Dr., School of Foreign Languages, Hubei University of Technology, Wuhan, Hubei Province, 430068, China, lichili@hbut.edu.cn

\section{Lianhua Tang}

Xiapu Primary School, Tongshan County, Xianning, Hubei Province, 437600, China, 1071344756@qq.com

\section{Shuang Zhang}

School of Arts and Communcation, Hubei Business College, Wuhan, Hubei Province, 430068, China, $470046501 @ q q . c o m$

Directed Motivational Currents (DMCs), as the latest theoretical development of second language (L2) motivation research, warrant more empirical investigations. In light of this, the present paper reports the results of a questionnaire survey on the features of DMCs among 245 English-as-a-Foreign-Language (EFL) learners at a technological university in China. The collected data were analysed by descriptive means and Independent T-test. The results show that most of the participants ever experienced DMCs in their English learning. Their experiences of DMCs mainly occurred in classroom settings. They reported a high level of DMCs and showed a strong willingness to experience them again. In addition, English majors were significantly different from non-English majors in some aspects of their DMCs. The findings of this study will be pedagogically implicative for maintaining L2 motivation among EFL learners in China and other similar contexts.

Keywords: directed motivational currents, chinese technological university students, DMC experience, English and non-English majors, EFL

\section{INTRODUCTION}

Second language (L2) motivation has long been the foci of second language acquisition studies since the 1950s. Research on L2 motivation has witnessed rapid development, undergoing several stages, namely, the socio-educational stage, the cognitive-situational stage, the process-oriented stage, the L2 self system stage, and the socio-dynamic stage (Dörnyei, et al., 2015).

Citation: Li, C., Tang, L., \& Zhang, S. (2021). Understanding Directed Motivational Currents among Chinese EFL Students at a Technological University. International Journal of Instruction, 14(2), 953968. https://doi.org/10.29333/iji.2021.14254a 
The latest development of L2 motivation research is the theory of Directed Motivational Currents (DMCs) proposed by Dörnyei and his colleagues. Directed Motivational Currents are described as the surges of a long period of intense and enduring motivation which is directed by a clear vision, with behavioral structure as its pathways and the fulfillment of short-term goal as its foundation (Dörnyei, et al, 2015; Muri \& Dörnyei, 2013). This view highlights the importance and necessity of understanding L2 motivation from such angles as time, individuals, and context.

DMCs have been both theoretically and empirically examined in some EFL contexts such as Sweden (Henry, et al., 2015), and Iran (Zarrinabadi \& Tavakoli, 2017). However, as a newly-proposed construct, DMCs need more empirical evidence in a wider context (Dörnyei, et al., 2015; Muri \& Dörnyei, 2013). This paper, therefore, aims to explore the features of DMCs among Chinese EFL learners. This study would contribute to enriching the current literature of DMCs research and shed light on maintaining L2 motivation in EFL contexts.

\section{LITERATURE REVIEW}

Credit of pioneering theoretical scholarship is given to Dörnyei and his associates. Muir and Dörnyei (2013) suggested that directed motivational currents should be integrated with vision in order to better understand the dispositions of L2 motivation. Dörnyei, et al. (2014) characterized directed motivational currents with three components, namely, a highly valued goal/vision, a salient facilitative structure, and positive emotionality. Dörnyei, et al. (2015) described directed motivational currents as a motivational drive which can energize long term sustained behavior and offer a potential for the effective creation and maintaining of motivational pathways in language learning classroom. They elaborated the theoretical underpinnings of directed motivational currents from such theories as dynamic systems theory, goal-setting theory, flow theory, future time perspective, and self-determination theory.

The first systematic empirical survey of DMCs was conducted by Henry, et al. (2015). In order to verify the rationality of the dimension of the DMCs, they conducted an investigation among some immigrants' experiences in learning Swedish as a second language. Their results showed that the motivational behavior of these immigrants is consistent with the structure of the DMCs put forward by Dörnyei and his colleagues, which further proves the value of the DMCs applied to the research of second language motivation.

Ghanizadeh and Jahedizadeh (2017) validated the Persian version of the DMC Disposition Scale proposed by Dornyei and his colleges (Dörnyei, et al., 2016; Muir, 2016). They identified a significant difference in DMCs between learners of elementary and upper-intermediate language proficiency levels. The upper-intermediate students experienced significantly more directed motivational currents than the elementary ones. They also found that both BA and MA learners experienced significantly higher level of directed motivational currents than their diploma counterparts.

Zarrinabadi and Tavakoli (2017) pointed out the predominance of theoretical nature of DMCs in early pertinent publications and the paucity of empirical research on the 
validity as well as the core characteristics of DMCs. In view of this, they investigated two Iranian teacher trainees' motivational experience and found them demonstrate the three key components of DMCs. They also called for more empirical studies to examine the extent to which DMCs can facilitate motivating individuals and the possibility of creating DMCs at group levels to assist learning a second/foreign language.

Ibrahim (2017) explored the parameters of the motivational currents among nine EFL learners and discovered five triggering factors for the emergence of their motivational currents. These five parameters include emergent opportunities, negative emotion, moments of realization/awakening, new information, and meeting others who shared the goal. He also found goal and perceived feasibility to be the two conditions for the beginning of a DMC.

To echo the call for more empirical evidence for the theoretical assumptions of the DMC construct (Henry, et al., 2015), Safdari \& Maftoon (2017) interviewed an Iranian adult EFL learner' DMC experience and found this learner's DMCs were characterized by goal-orientedness, salient facilitative structures, and positive emotionality. Their study confirmed the construct tenets of DMCs. They also suggested more empirical studies to unveil the tenets of the construct of DMCs among different individuals in contexts and communities.

Pedagogical implications of DMCs have drawn attention. Dastgahian and Ghonsooly (2018) experimented the effectiveness of creating directed motivational currents for EFL learning. They initiated a directed motivational current by introducing some spiritual vocabularies to 63 pre-tertiary EFL learners and found it facilitative in assisting the surge of an initial motive and energizing the learners to perform better. Pietluch (2018) explored the correlation between self-efficacy and directed motivational currents by investigating 212 adult EFL learners, and found a strongly positive correlation between DMCs and self-efficacy. That is, an increase in self-efficacy would also lead to a strong surge of directed motivational currents.

The theory of the Directed Motivational Currents has gradually drawn attention in China. Chang (2016) introduced DMCs theory into China and explicated the components of DMCs. He commented that the theory of DMCs has contributed to a new conceptual framework for L2 motivation research, and a clarification of the tenets and dispositions of L2 motivation. Wang, et al. (2017) described the features of DMCs construct. While pointing out its theoretical and practical value for both L2 motivation research and foreign language learning and teaching, they suggested more empirical studies to validate the DMC concept. They suggested that teachers should create favorable conditions for the generation of directed motivation currents in L2 classroom and should help learners and maintain their motivational momentum.

Few empirical studies were reported in China. Chang (2017) investigated the motivation dynamics throughout the undergraduate English learning experiences of ten postgraduates of English. He found motivational currents in the participants' motivational trajectories. This fluctuation was mainly related to such attractor states as various English exams, expected return, campus atmosphere, and classroom instruction. 
The participants displayed some individual motivational variations in two DMCs dimensions, namely, goal/vision-orientedness and facilitative structure. Yin (2018) explored the features and dynamic trends of DMCs in L2 writing. He found that the DMCs trajectory was associated with the time scale of goal setting among the L2 writing learners. He also identified the characteristics of salient facilitative structure and positive emotionality of DMC in L2 writing. He suggested enhancing learners' motivation by helping them create vision for learning L2 writing. Ning and Cai (2019) validated the construct of DMCs by conducting an interview based case study involving four BA graduates of English. They discovered a presence of salient facilitative structure, positive emotionality and long term identity investment goals. They called for more research on DMCs on both individual and group levels.

In summary, the concept of the Directed Motivational Currents proposed by Dörnyei and his colleagues has attracted wide attention in L2 motivation. However, the exploration of this theory is still in the theoretical exploration stage, and is limited to the discussion of its constituent dimension. Its dimension needs to be further verified with more empirical studies. Therefore, this study aims to enrich the present literature on DMCs and tries to focus on the DMCs of a group of students at a technological university in China.

\section{METHOD}

\section{Research Questions}

This study intends to carry out an investigation into the Directed Motivational Currents among EFL students at a technological university in China. It aims to address the following questions:

Question 1: What is the experience in DMCs among the participants?

Question 2: What is the level of DMCs among the Participants?

Question 3: What are the differences in DMCs between English and Non-English Majors?

\section{Participant}

The participants of the research comprise 245 EFL students from a technological university in central China. The profile of the participants is as follows: Male participants numbered 55, while 190 of them were female. Their ages varied from 17 to 30 years old, with an average age of 21.4122. Among these participants, 109 were English majors and 136 were non-English majors. There were 19 undergraduate freshmen, 43 sophomores, 39 juniors, 81 seniors, and 63 first year postgraduates. Besides, 111 of the surveyed participants were from countryside, 86 from towns, and 48 from cities. As for their self-evaluation of English proficiency, only three of them scaled themselves to be at an advanced level, 147 at an intermediate level, and 95 at a low level. 
Table 1

Background information of the participants

\begin{tabular}{|c|c|c|c|c|c|c|}
\hline \multirow{2}{*}{ Grade of Education } & \multirow{2}{*}{$\frac{\text { Freshmen }}{19}$} & \multirow{2}{*}{$\begin{array}{l}\text { Sophomore } \\
43\end{array}$} & \multirow{2}{*}{$\begin{array}{l}\text { Junior } \\
39\end{array}$} & \multirow{2}{*}{$\begin{array}{l}\text { Senior } \\
81\end{array}$} & \multirow{2}{*}{$\begin{array}{l}\text { Postgraduate } \\
63\end{array}$} & \multirow{2}{*}{$\begin{array}{l}\text { Sum } \\
245\end{array}$} \\
\hline & & & & & & \\
\hline \multirow{3}{*}{ Major } & English & \multicolumn{3}{|c|}{109} & & \\
\hline & \multicolumn{2}{|c|}{ Non-English } & \multicolumn{2}{|l|}{136} & & \\
\hline & \multicolumn{2}{|l|}{ Sum } & \multicolumn{2}{|l|}{245} & & \\
\hline \multirow{2}{*}{ Age } & Minimum & Maximum & \multicolumn{2}{|c|}{ Mean } & \multicolumn{2}{|c|}{ Standard Deviation (SD) } \\
\hline & 17 & 30 & \multicolumn{2}{|c|}{21.4122} & \multicolumn{2}{|l|}{2.04995} \\
\hline \multirow{2}{*}{ Gender } & \multicolumn{2}{|l|}{ Male } & \multicolumn{2}{|c|}{ Female } & & \\
\hline & \multicolumn{2}{|c|}{55} & \multicolumn{2}{|c|}{190} & & \\
\hline \multirow{2}{*}{ Hometown } & \multicolumn{2}{|c|}{ Countryside } & \multicolumn{2}{|c|}{ Town } & \multicolumn{2}{|l|}{ City } \\
\hline & \multicolumn{2}{|l|}{111} & \multicolumn{2}{|c|}{86} & \multicolumn{2}{|l|}{48} \\
\hline \multirow{2}{*}{$\begin{array}{l}\text { Self assessment of } \\
\text { English Proficiency }\end{array}$} & \multicolumn{2}{|l|}{ Advanced } & \multicolumn{2}{|c|}{ Intermediate } & \multicolumn{2}{|l|}{ Low } \\
\hline & \multicolumn{2}{|l|}{3} & & & 95 & \\
\hline
\end{tabular}

\section{Instrument}

In order to find out the Directed Motivational Currents among EFL University Students, the Chinese version of DMC Disposition Questionnaire designed and validated by Muri (2016) was employed. Before finalizing the questionnaire, four sophomores were invited for a pilot study so as to check whether the questionnaire items could truly reflect their English language learning experiences and whether there were misleading or inaccurate expressions in the questionnaire items.

The questionnaire comprised four parts: (1) The first part (seven items) asked for the background information of the participants; (2) The second part (six items) examined the participants' DMC experiences. Item 1-3 followed a Five-Likert scale from Strongly Disagree (1) to Strongly Agree (5). Item 4 inquired the participants' frequency of experiencing DMCs. Item 5 related to the length of time when experiencing DMCs. Item 6 invited them to scale their motivational intensity in their experience of DMCs. (3) The third part (fifteen items) was the main body of the questionnaire and asked the participants to tick the length and intensity of their DMCs experiences. Item 7-19, except for Item 13, followed the Five-Likert scale from Strongly Disagree (1) to Strongly Agree (5). Item 5 related to their self-perceived English language proficiency when experiencing DMCs. (4) The fourth part (one item) asked whether the participants would like to experience DMCS again and whether they witnessed others experiencing DMCs. The Cronbach Alpha of the questionnaire items was .803, indicating a sound internal consistency within these items and showing reasonably high reliability of the instrument.

\section{Data Collection}

The data were collected in the fall semester of the 2019 academic year. The authors firstly obtained consent from the English language teachers of the participants before formally administering the questionnaire survey. Then, during the break of the class, 280 copies of the questionnaire were distributed by the authors to the participants. 
Objectives of this survey were briefed to the participants before they answered to the questionnaire items. They were also guaranteed that this survey would not exert any detrimental effect on their final exam scores, and their information would be definitely kept confidentially. Finally, 276 copies of the questionnaire were returned, 245 of them valid after the incomplete and wrongly answered ones were removed.

\section{Data Analysis}

The collected data were processed by means of Statistic Package for Social Science 20.0 (SPSS 20.0). Descriptive techniques such as frequency and percentage were calculated to answer Research Question 1 regarding the participants' experiences of DMCs. Then, mean values were measured to seek answers to Research Question 2 relating to the motivational intensity when the participants' experienced DMCs. Besides, inferential analysis method such as Independent T-test was performed to check whether there were significant differences in DMCs between English majors and non-English majors (Research Question 3).

\section{FINDINGS}

\section{Experiences of DMCs among the Participants}

In order to answer Research Question 1 which investigated the respondents' experiences of DMCs, the responses of the participants to the questionnaire items were subjected to the calculation of frequency with SPSS 20.0.

Table 2

The participants' experiences of DMCs

\begin{tabular}{llllll}
\hline Item & $\mathrm{SD}(\%)$ & $\mathrm{D}(\%)$ & $\mathrm{N}(\%)$ & $\mathrm{A}(\%)$ & $\mathrm{SA}(\%)$ \\
$\begin{array}{l}\text { 1. Recognized the } \\
\text { intense motivation }\end{array}$ & $3(1.22 \%)$ & $8(3.27 \%)$ & $87(35.51 \%)$ & $120(48.98 \%)$ & $27(11.02 \%)$ \\
\hline $\begin{array}{l}\text { 2. Experienced it } \\
\text { while doing a project }\end{array}$ & $2(0.82 \%)$ & $8(3.27 \%)$ & $65(17.24 \%)$ & $137(55.92 \%)$ & $33(13.47 \%)$ \\
\hline $\begin{array}{l}\text { 3. Experienced it } \\
\text { while learning English }\end{array}$ & $5(2.04 \%)$ & $22(8.98 \%)$ & $114(46.53 \%)$ & $90(36.73 \%)$ & $14(5.71 \%)$ \\
\hline
\end{tabular}

Table 2 reports the participants' experiences of directed motivational currents. 120 (48.98\%) participants agreed that they recognized the intense motivation (Item 1), and $27(11.02 \%)$ of them strongly agreed. Almost two thirds of them acknowledged an experience of DMCs in their previous learning.

When being asked whether they experienced intense motivation while doing a project (Item 2), $137(55.92 \%)$ and $33(13.47 \%)$ participants agreed and strongly agreed respectively. It seems that over two thirds of the surveyed respondents were intensely motivated when they were involved in a project.

Besides, $90(36.73 \%)$ and $14(5.71 \%)$ of the participants respectively agreed and strongly agreed with Item 3 which asked them whether they experienced intense motivation while learning English). This finding revealed that, though lower than that in Item 1 and 2, there was still a decent number of students who experienced intense motivation in their English study. 
When they were further asked about the frequency of experiencing a project of the motivational intensity (Item 4), $2.9 \%$ of them said that they never had such experiences, $11 \%$ of them experienced once but not that intensely, $59.2 \%$ of them had several times but not so intense experiences. By contrast, $11 \%$ of them expressed that they once had such an intense experience, and $15.9 \%$ experienced an intense DMCs several times. The results indicated that over half of the participants experienced intense motivation in doing projects.

With regard to the language proficiency level when they experienced intense motivation (Item 20), 10.2\% of the participants rated themselves as beginners, $24.5 \%$ of them believed them to be pre-intermediate learners, $38.4 \%$ of them claimed them to be at intermediate level, $25.3 \%$ of them considered themselves to be upper-intermediate learners, but only $1.6 \%$ of them chose themselves to be at advanced level. It is revealed that a majority of the surveyed students rated themselves $t o$ be at intermediate level or below.

When being asked about the place where they experienced DMCs (Item 21), 37.1\% and $33.1 \%$ of the participants responded that they experienced the intense and enduring motivation in their English learning at school and university respectively. In other words, most of their DMCs experiences occur in formal instruction contexts such as language class on campus. $24.1 \%$ of the participants claimed that they experienced DMCs while learning English on their own. Only 5.7\% of them (14 students) ever experienced DMCs at private language schools. It seems that formal classroom instruction on campus is one of the key factors leading to the emergence of DMCs.

In addition, when being inquired whether they ever witnessed other people around them experiencing DMCs (Item 22), 52.7\% of the participants claimed that they have witnessed others experiencing DMCs and $31.4 \%$ of them are not sure, while only $15.9 \%$ denies it.

\section{DMCs Level among the Participants}

For the purpose of measuring the level of DMCs among the participants (Research Question 2), mean values of Item 7-19 except for Item 13 were calculated. According to Oxford (1990), the mean of a questionnaire item following a Five-Likert scale indicates the level of strategy use of a participant. Specifically, the participants are considered to demonstrate a high level of frequency if the mean values are between 3.5 and 5.0, a medium level between 2.5 and 3.4, and a low level between 1.0 and 2.4. This research adopted her criteria to assess the participants' level of DMCs in their English language learning.

The participants' overall level of DMCs was firstly examined by their self-perceived motivational intensity on a Five-Likert scale from being not very intense to very intense (Item 6). The mean value of their responses to the statement is $3.6694(\mathrm{SD}=0.87361)$, indicating a high level of DMCs among the participants.

One more angle to understand the participants' overall DMCs level is the length of the period that last DMCs (Item 5). 42\% of the participants experienced the intense motivation in any context for less than 1 month, indicating that their DMCs lasted not 
long. $33.1 \%$ of them responded that their DMCs usually lasted for one to two months, and $9.8 \%$ of theirs would last two to four months. Only $4.9 \%$ of them indicated that their DMCs lasted for four to six months, but $10.2 \%$ of the participants said that their DMCs would stay for over six months.

Table 3

Levels of the participants' DMCs $(\mathrm{N}=245)$

\begin{tabular}{|c|c|c|c|c|}
\hline Item & Min. & Max. & Mean & SD \\
\hline 7 When looking back now, I have very good memories of this time. & 2.00 & 5.00 & 3.8367 & 0.80843 \\
\hline $\begin{array}{l}\text { During this time I was able to work more productively than I } \\
\text { usually can. }\end{array}$ & 1.00 & 5.00 & 3.9755 & 0.71246 \\
\hline 9 I surprised myself with how much I was able to do. & 1.00 & 5.00 & 3.6694 & 0.78984 \\
\hline 10 Many times it felt like a real struggle to keep going. & 1.00 & 5.00 & 3.8408 & 0.73214 \\
\hline 11 This experience helped me to all I had wanted to and more. & 2.00 & 5.00 & 3.8000 & 0.66899 \\
\hline $\begin{array}{l}12 \text { I think something special happened to me during this experience-it } \\
\text { was amazing. }\end{array}$ & 1.00 & 5.00 & 3.6653 & 0.78028 \\
\hline 14 At the time, the project became a central part of my life. & 1.00 & 5.00 & 3.7388 & 0.76094 \\
\hline $\begin{array}{l}\text { The people around me could see that I was experiencing something } \\
\text { special. }\end{array}$ & 1.00 & 5.00 & 3.4898 & 0.74993 \\
\hline $\begin{array}{l}\text { It did not feel like hard work at the time- I was just caught in the } \\
\text { flow! }\end{array}$ & 1.00 & 5.00 & 3.1796 & 0.84954 \\
\hline 17 I remember thinking about my goal all the time. & 1.00 & 5.00 & 3.6939 & 0.76833 \\
\hline 18 I often imagined myself achieving my final goal. & 1.00 & 5.00 & 3.7551 & 0.85724 \\
\hline 19 It was a really enjoyable experience. & 1.00 & 5.00 & 3.7633 & 0.75278 \\
\hline
\end{tabular}

The participants' overall high level of DMCs is echoed in their responses to the individual items (Table 3). The mean value for Item 7 was 3.8367 (> 3.5), indicating that the participants had a very good memory of DMCs experience. The mean value for Item 8 was 3.97557 (> 3.5), suggesting a high level of ability among the participants to work more productively than they usually could when experiencing DMCs. A high level was also found with Item 9 (mean $=3.6694)$, showing that the participants were very surprised that they could achieve that much.

This strong feeling of a DMCs experience seems to be a struggle for the participants to try to keep going (Item 10, mean $=3.8408$ ). When experiencing DCMs, they felt that this experience would facilitate them to accomplish all they had ever wanted to do (Item 11 , mean $=3.8000)$. During this process, they demonstrated a strong belief that something special and amazing would happen to them (Item 12, mean $=3.6653$ ).

While the participants reported a strong feeling about their experience that the project they were being involved became a central part of their life (Item 14, mean $=3.7388$ ), they showed a medium level of DMCs experience in Item $15($ mean $=3.4898)$ and Item 16 (mean $=3.1796)$. They seemed to be caught in the flow of this DMCs experience and were observed by others that they were experiencing something special.

The mean values for Item 17 and Item 18 are 3.6939 and 3.7551 respectively. This result indicated that the experience of DMCs functioned as a good reminder to them of keeping their goals of learning and of promoting their future image of achieving the final goal. The mean value for Item 19 (mean $=3.7633$ ) revealed that the participants considered their DMCs experience to be an enjoyable journey. 


\section{Differences in DMCs between English and Non-English Majors}

In order to examine the differences in DMCs between English majors and non-English majors (Research Question 3), an Independent T-test was performed. Table 4 reports the results of the Independent T-test.

The two groups of the participants showed certain similarities and differences in their DMCs. Firstly, the two groups both demonstrated a high level of DMCs on most of the questionnaire items. The mean values of the English majors on Item 7 (mean $=3.7890)$, Item $8($ mean $=4.0367)$, Item $9($ mean $=3.8257)$, Item $10($ mean $=3.9358)$, Item 11 $($ mean $=3.8991)$, Item $12($ mean $=3.7798)$, Item $14($ mean $=3.7431)$, Item $15($ mean $=$ $3.5229)$, Item $17($ mean $=3.7248)$, Item $18($ mean $=3.8440)$, and Item 19 (mean $=$ 3.8532) were all above 3.5, indicating a high level of DMCs among the English majors on these items. The mean value of this group on Item 16 was 3.2936, which revealed a medium level of their DMCs.

Similarly, the mean values of the Non-English majors on Item 7 (mean $=3.8750)$, Item $8($ mean $=3.9265)$, Item $9($ mean $=3.5441)$, Item $10($ mean $=3.7647)$, Item $11($ mean $=$ 3.7206), Item $12($ mean $=3.5735)$, Item $14($ mean $=3.7353)$, Item $17($ mean $=3.6691)$, Item 18 (mean = 3.6838), and Item $19($ mean $=3.6912)$ were all above 3.5, which indicated a high level of DMCs among the Non-English majors on these items. Besides, the Non-English majors revealed a medium level of DMCs on Item $15($ mean $=3.4632)$ and Item $16($ mean $=3.0882)$.

Table 4

Differences in DMCs between english and non-english majors

\begin{tabular}{|c|c|c|c|c|c|}
\hline Item & Group & Number & Mean & SD & P [Sig.(2-tailed)] \\
\hline \multirow{2}{*}{7} & English Majors & 109 & 3.7890 & 0.88269 & \multirow{2}{*}{0.409} \\
\hline & Non-English Majors & 136 & 3.8750 & 0.74473 & \\
\hline \multirow{2}{*}{8} & English Majors & 109 & 4.0367 & 0.66565 & \multirow{2}{*}{-0.224} \\
\hline & Non-English Majors & 136 & 3.9265 & 0.74667 & \\
\hline \multirow{2}{*}{9} & English Majors & 109 & 3.8257 & 0.74342 & \multirow{2}{*}{-0.005} \\
\hline & Non-English Majors & 136 & 3.5441 & 0.80616 & \\
\hline \multirow{2}{*}{10} & English Majors & 109 & 3.9358 & 0.69755 & \multirow{2}{*}{-0.067} \\
\hline & Non-English Majors & 136 & 3.7647 & 0.75263 & \\
\hline \multirow{2}{*}{11} & English Majors & 109 & 3.8991 & 0.69315 & \multirow{2}{*}{-0.038} \\
\hline & Non-English Majors & 136 & 3.7206 & 0.64050 & \\
\hline \multirow{2}{*}{12} & English Majors & 109 & 3.7798 & 0.76204 & \multirow{2}{*}{-0.039} \\
\hline & Non-English Majors & 136 & 3.5735 & 0.78535 & \\
\hline \multirow{2}{*}{14} & English Majors & 109 & 3.7431 & 0.69925 & \multirow{2}{*}{-0.935} \\
\hline & Non-English Majors & 136 & 3.7353 & 0.80953 & \\
\hline \multirow{2}{*}{15} & English Majors & 109 & 3.5229 & 0.75273 & \multirow{2}{*}{-0.537} \\
\hline & Non-English Majors & 136 & 3.4632 & 0.74940 & \\
\hline \multirow{2}{*}{16} & English Majors & 109 & 3.2936 & 0.90577 & \multirow{2}{*}{-0.060} \\
\hline & Non-English Majors & 136 & 3.0882 & 0.79322 & \\
\hline \multirow{2}{*}{17} & English Majors & 109 & 3.7248 & 0.78021 & \multirow{2}{*}{-0.574} \\
\hline & Non-English Majors & 136 & 3.6691 & 0.76065 & \\
\hline \multirow{2}{*}{18} & English Majors & 109 & 3.8440 & 0.91464 & \multirow{2}{*}{-0.146} \\
\hline & Non-English Majors & 136 & 3.6838 & 0.80464 & \\
\hline \multirow{2}{*}{19} & English Majors & 109 & 3.8532 & 0.73062 & \multirow{2}{*}{-0.093} \\
\hline & Non-English Majors & 136 & 3.6912 & 0.76512 & \\
\hline
\end{tabular}


A further examination of the mean values on each item reveals salient differences between the two groups. The mean values for the English majors on Item 8, 9, 10, 11, $12,14,15,16,17,18$, and 19 were higher than those of the Non-English majors. This result indicated that the English majors had a higher level of DMCs on these items than their counterparts. Further, there is only one item (Item 7) whose mean value for the Non-English majors was higher than that of the English majors. This result suggested that the Non-English group were at a higher level only on this one item than their counterparts.

The aforementioned differences between the two groups were further securitized through Independent T-test (Table 4). The P values [Sig. (2-tailed)] for Item 9, Item 11, and Item 12 between the two groups were $0.005,0.038$ and 0.039 respectively, which were all below the 0.05 level. This result suggested a significant difference in these three items between the two groups. The English majors were more significantly surprised at themselves that they were able to do that much than their counterparts (Item 9). The former more significantly felt that this DMCs experience helped them achieve all they had wanted than the latter (Item 11). The English cohort also seemed to more significantly feel something special happened to them than the non-English group (Item 19).

\section{DISCUSSION}

This study aimed to investigate the experience and level of DMCs among tertiary students at a technological university in China. It also intended to explore the differences in DMCs between English majors and non-English major students. To this end, a questionnaire survey drawing on sources of previous studies was administered and proved to be of reasonable reliability.

The first research question surveyed the participants' DMCs experience. It was found that most of the surveyed participants ever experienced DMCs, or witnessed others experience DMCs in their English learning. Besides, most of the participants are willing to experience DMCs again because they believed that the DMCs experiences could contribute to a better acquisition of the English language. These results corroborated some previous studies both in China (i.e., Chang, 2017; Ning \& Cai, 2019) and other similar EFL contexts (Safdari \& Maftoon, 2017; Zarrinabadi \& Tavakoli, 2017).

This study also found that the participants were at intermediate level of English proficiency when they experienced DMCs. Such experiences were often observed at school or university settings. These results suggested that classroom was the major place for the technological tertiary students to learn English. This is because formal classroom instruction is of the primary source for English learning in EFL contexts (Sak, 2019). These findings indicated that Chinese tertiary students at technological universities are also strongly motivated in their English learning and showed similarities in L2 motivation with other groups of EFL learners.

The second research question investigated the level of DMCs among the participants. It was found that the participants had a high level of DMCs in their English learning, but this high level was often noticed to last only within 1-2 month among most of the 
participants. This result revealed that L2 motivation might be fluctuating with specific conditions as attractors at different stages of their English learning (Chang, 2017; Li \& Qian, 2018). Learning tasks/projects as inquired in the questionnaire items and exams presented at different stages would function as attractors contributing to the surges of motivational intensity among EFL learners (Chang, 2017; Henry \& Davydenko, 2020; Ibrahim, 2020).

This finding also suggested lack of motivation among Chinese tertiary learners at technological universities ( $\mathrm{Li}$, et al., 2020). Due to the limited English language proficiency in the national English matriculation test of the participants in contrast to those of the key universities, the peripheral position of English education and the examoriented teaching methodologies at those technological universities (Cai, 2017), they were often found to be demotivated though they might sometimes be temporarily motivated when periodical attractors appeared (Chang, 2017).

The third research question explored the differences in DMCs between English major and non-English major students. Significant differences were identified between the two groups. The English majors were found to be more significantly surprised at themselves that they were able to do that much than their counterparts. Their DMCs experience more significantly helped them achieve all they had wanted than the non-English group. They also seemed to more significantly feel something special that was happening to them than the non-English fellows.

The differences in DMCs between the two groups might be explained as follows. The first is the differences in English curriculum. English majors usually attend English courses every day but non-English majors do not, indicating more opportunities for the former to be exposed to the target language. Consequently, English majors might feel more confident and surprised at what they could achieve than their counterparts. The second is the variation of motivational levels between the participants. English majors are usually strongly motivated either because of their intrinsic interest in taking English as their major or because of the pushing force of their identity as English major to pursue English proficiency. However, non-English majors at technological universities are often less motivated. As pointed out earlier, technological universities in China often positioned themselves to be application-oriented, which highlighted the importance of application skills instead of foreign language competence (Wen, 2015). Besides, the exam-oriented teaching methodologies result in the loss of interest in English course among the students. The students could not see the connection in English learning with what they really need in their professional field. This gap might thus make them only temporarily and instrumentally motivated (Cai, 2017).

\section{CONCLUSION}

This study surveyed the directed motivational currents (DMCs) experienced by Chinese tertiary EFL learners at a technological university. It has found that most of the surveyed respondents ever experienced DMCs and had a good comment on this experience. They showed a high level of motivational intensity when experiencing DMCs, though this intensity would often last for limited time duration. It has also identified some 
significant differences in DMCs between English majors and non-English majors. These findings confirmed some previous studies and suggested both similarities and differences in DMCs experience between Chinese technological tertiary EFL learners and other groups of English learners.

These findings have certain pedagogical implications. Firstly, since those technological tertiary EFL learners were ever strongly impressed with their DMCs experience, it might be important for teacher to help the learners realize this and thus to increase their sense of engagement into their English learning. Secondly, since most of the participants' DMCs experiences were taking place in schools or at university, it is thus essential for teachers to improve their classroom teaching methodologies so as to create more opportunities for the students to experience DMCs in class and further help them sustain these currents. Thirdly, it is also necessary for both teachers and educational decision makers to design English curriculum based on the genuine needs of the non-English major students at technological universities and other similar institutions of higher education so that they could sense the value of English learning for their professional study and work in the future.

This study has some shortcomings in terms of the size of sample population and sources of data. It is therefore cautioned when generalizing the findings of this study. Future research may be conducted with a larger population and triangulated methods like interviews and classroom observation so as to further verify the findings of this present study.

\section{ACKNOWLEDGEMENTS}

This study is supported by the Social Sciences Research Fund of Hubei Provincial Department of Education (Exploring L2 Motivation to Learn English among Technological University Students: A DMCs Perspective, No. 18Y067) and the Social Sciences Research Fund of Hubei University of Technology (Investigating DMCs to Learn English among Technological University Students, No. 2017SW0305).

\section{REFERENCES}

Cai, J. G. (2017). Challenges to foreign language teaching concepts: Take College English Teaching Guidelines as an example. Foreign Language Education, (1), 6-10.

Chang, H. C. (2016). Directed Motivational Current: A new development in L2 motivational theory. Modern Foreign Languages, (5), 704-713.

Chang, H. C. (2017). Exploring English majors' learning motivational dynamics: a qualitative study based on DMC. Foreign Language World, (3), 39-47.

Dastgahian, B. S. \& Ghonsooly, B. (2018). Managing Directed Motivational Currents of Religious Texts on English Language Achievement: A Mixed-Methods Study. Asian EFL Journal, 20(4),162-183

Dörnyei, Z., Ibrahim, Z. \& Muri, C. (2015). Directed Motivational Currents: Regulating Complex Dynamic Systems through Motivational Surges. In Z. Dornyei, P. MacIntyre, 
\& A. Henry (Eds.) Motivation dynamics in language learning (pp. 95-105). Bristol: Multilingual Matters.

Dörnyei, Z., Muir, C. \& \& Ibrahim, Z. (2014). Directed Motivational Currents Energising language learning by creating intense motivational pathways. In D. Lasagabaster, A. Doiz, \& J. M. Sierra (Eds.). Motivation and Foreign Language Learning: From theory to practice (pp.9-29). Amsterdam, the Netherlands: John Benjamins.

Dörnyei, Z., Henry, A., \& Muir, C. (2016). Motivational currents in language learning: Frameworks for focused interventions. New York, USA: Routledge.

Ghanizadeh, A., \& Jahedizadeh, S. (2017). The Implementation of the Dynamic WebBased Persian Scale among Iranian EFL Learners. Journal of Teaching Language Skills, 36(1), 27-56. DOI: 10.22099/jtls.2017.23952.2159

Henry, A., Davydenko, S., \& Dörnyei, Z. (2015). The anatomy of directed motivational currents: Exploring intense and enduring periods of L2 motivation. Modern Language Journal, 99(2), 329-345. DOI: 10.1111/modl.12214

Henry, A., \& Davydenko, S. (2020). Thriving? Or Surviving? An Approach-Avoidance perspective on Adult Language Learners' Motivation. The Modern Language Journal, (2), 363-380. DOI: $10.1111 / \bmod 1.12635$

Ibrahim, A. (2017). Parameters Inducing Motivational Surges in Second Language Learning. UKH Journal of Social Sciences, (1), 24-33. DOI: 10.25079/ukhjss.v1n1y2017.24-33

Ibrahim, Z. (2020). Sustained flow: Affective obsession in second language learning. Frontiers in Psychology, 10, 1-13. DOI: 10.3389/fpsyg.2019.02963

Li, C. L., \& Qian, J. H. (2018). Investigating changes in demotivation among Chinese EFL learners from an activity theory perspective. International Journal of English Linguistics, (1), 44-53. DOI:10.5539/ijel.v8n1p44

Li, C. L., Dou, R., \& Zhang, S. (2020). A Correlational Study on Psychological Resilience and L2 Demotivation among Chinese EFL Learners. Revista Argentina de Clínica Psicológica, (3), 670-681. DOI:10.24205/03276716.2020.770

Muir, C. (2016). The dynamics of intense long term motivation in language learning: Directed Motivational Currents in theory and practice. $\mathrm{PhD}$ thesis, University of Nottingham.

Muri, C., \& Dörnyei, Z. (2013). Directed Motivational Currents: using vision to create effective motivational pathways. Studies in Second Language and Teaching, (3), 357375.

Ning, J. G. \& Cai, J. T. (2019). DMC Case Study from the DST's Perspective. Foreign Language Education, (3), 69-75. 
Oxford, R. L. (1990). Language learning strategies: What every teacher should know. New York: Newbury House.

Pietluch, A. (2018). Extraordinary Motivation or a High Sense of Personal Agency: The Role of Self-Efficacy in the Directed Motivational Currents Theory. New Horizons in English Studies, (3), 45-56. DOI: 10.17951/nh.2018.45

Safdari, S., \& Maftoon, P. (2017). The Rise and Fall of Directed Motivational Currents: A Case Study. The Journal of Language Teaching and Learning, (1), 43-54

Sak, M. (2019). Contextual Factors that Enhance and Impair Directed Motivational Currents in Instructed L2 Classroom Settings. Novitas-ROYAL, (2), 155-174.

Wang, X. L., Yang, L. R. \& Yan, H. J. (2017). Directed Motivational Currents: A Study of L2 Motivation from the Perspective of DST. Contemporary Foreign Languages Studies, (4), 49-54.

Wen, Q. F. (2015). Developing a theoretical system of production-oriented approach in language teaching. Foreign Language Teaching and Research, (4), 547-558.

Yin, H. S. (2018). Directed Motivational Current in Second Language Writing. Foreign Language Research, (2), 64-68.

Zarrinabadi, N., \& Tavakoli, M. (2017). Exploring Motivational Surges Among Iranian EFL Teacher Trainees: Directed Motivational Currents in Focus. TESOL Quarterly, (1), 155-166. DOI: $10.1002 /$ tesq.332 


\section{Appendix}

\section{Dear students:}

Hello!

Thank you for taking the time to participate in this questionnaire. The purpose of our survey is to understand your motivation for English learning. The questionnaire is anonymous. The results are for academic purposes only and promise absolute confidentiality, so there is no need to worry about it. Thank you for your participation and cooperation! Enjoy your study and life!

\section{Part 1: Your basic information}

1. Gender : A) male; B) female

2. Age:

3. Your grade : A) freshman B) sophomore; C) junior; D) senior;

4. Your major :

5. English scores (please fill in your according to your personal situation)

1 ) Gaokao: 2 ) TEM4:

3 ) TEM8 : 4 ) CET-4 :

5 ) CET-6 :

6. Hometown: A) countryside; B) town; C) city

7. Self assessment of English proficiency: A) advanced ; B) intermediate; C) low

\section{Part 2:}

We find accounts on the Internet of people being totally absorbed in VERY INTENSE PROJECTS which motivate them for weeks or even months at a time.

These people say things like:

- "I think about this project day and night-I feel like it's taken over my life!"

- "I'm amazed I've been able to stay so focused for so long, I'm so enjoying it that putting in all the work feels easy!"

- "I never thought I could achieve so much!"

- "My friends can definitely see that something special is happening to me, they say they've never seen me so motivated!"

- "I wish I could experience this type of motivation while working towards all my goals!" Please answer the following questions by marking the appropriate answer.

\begin{tabular}{l} 
Item \\
\hline $1 \quad$ I recognize this type of intense motivation \\
\hline 2 I have personally experienced this type of intense motivation while doing a \\
project
\end{tabular}


About your experience of this kind of intense motivation if you have experienced this more than once, please choose the most memorable time. This can be from ANY context (not only language learning).

5. How long did this experience last?

1) $\square$ Less than 1 month 2) $\square$ 1-2 months $\quad$ 3) $\square$ 2-4 months

4) $\square$ 4 6 months $\quad$ 5) $\square$ Longer than 6 months

6. Please mark on the scale below how intense your motivation felt throughout this period

$$
\begin{array}{lllll}
1 & 2 & 3 & 4 & 5
\end{array}
$$

Not very intense $\square \square \square \square \square$ Very intense

Part 3 : About your intense motivation project

\begin{tabular}{|c|c|c|c|c|c|c|}
\hline Item & & 1 & 2 & 3 & 4 & 5 \\
\hline 7 & When looking back now, I have very good memories of this time & & & & & \\
\hline 8 & During this time I was able to work more productively than 1 usually can & & & & & \\
\hline 9 & I surprised myself with how much I was able to do & & & & & \\
\hline 10 & Many times it felt like a real struggle to keep going & & & & & \\
\hline 11 & This experience helped me to achieve all I had wanted to and more & & & & & \\
\hline 12 & $\begin{array}{l}\text { I think something special happened to me during this experience - it was } \\
\text { an amazing time }\end{array}$ & & & & & \\
\hline
\end{tabular}

$* 1=$ Strongly disagree, $2=$ Disagree, $3=$ Neither agree nor disagree, $4=$ Agree, $5=$ =Strongly agree

13.Would you like to experience this type of intense motivation again?

1. $\square$ Yes 2. $\square$ No

A little more about your intensive project experience.

\begin{tabular}{|c|c|c|c|c|c|c|}
\hline Item & & 1 & 2 & 3 & 4 & 5 \\
\hline 14 & At the time, this project became a central part of my life & & & & & \\
\hline 15 & The people around me could see that 1 was experiencing something special & & & & & \\
\hline 16 & It didn't feel like hard work at the time -1 was just caught up in the flow! & & & & & \\
\hline 17 & I remember thinking about my goal all the time & & & & & \\
\hline 18 & I often imagined myself achieving my final goal & & & & & \\
\hline 19 & It was a really enjoyable experience & & & & & \\
\hline
\end{tabular}

Please answer the following two questions ONLY if you have experienced this type of intense motivation in the context of English learning

20. How would you rate your English proficiency level at the time you experienced this intense period of motivation?
1) $\square$ Beginner
2) $\square$ Pre- intermediate 3) $\square$ Intermediate
4) $\square$ Upper- intermediate 5) $\square$ Advanced

21. Please tick the below statement which was most appropriate to you at the time you experienced this

1) $\square$ I was studying the language at school

2) $\square$ I was studying the language at university

3) $\square$ I was studying the language at a private language school

4) $\square$ I was studying the language on my own

Part 4:

22. Have you seen this type of motivation in people around you?

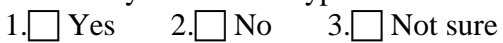

